\title{
AC 2010-760: NASA MOONBUGGY SENIOR DESIGN PROJECT AS AN ASSESSMENT TOOL AND POTENTIAL CAREER PATH IN AEROSPACE
}

\section{Nidal Al-Masoud, Central Connecticut State University}

Dr. Al-Masoud, Associate Professor, earned his Ph.D. in Mechanical Engineering from The University at Buffalo, The State University of New York in 2002. Dr. Al-Masoud has taught at both graduate and undergraduate level courses at University at Buffalo, he joined Central Connecticut State University as an Assistant Professor in 2003. At CCSU, he teaches courses mechanics, Thermo-fluid, and Control Systems and Dynamics. Dr. Al-Masoud research interests are in the fields of Control Systems and Dynamics, HVAC systems, and Engineering Education. He has numerous journal and conference proceeding publications in the aforementioned areas, and was the winner of the ASEE Mechanics Division Best paper Award in 2006. He has an extensive experience in Heating Ventilation and Air Conditioning Systems (HVAC) design. Dr. Al-Masoud is very active in many Professional Societies. He serves on the Board of Directors of American Society of Mechanical Engineers, Hartford Section; he is also the Faculty advisor of CCSU-ASME Student section. He is a member of the American Institute of Astronauts and Astronautics (AIAA), IEEE, ASEE.

\section{Viatcheslav Naoumov, Central Connecticut State University}

Dr. Viatcheslav Naoumov - Ph.D., Dr.Sc. Associate Professor, Distinguished Scientist of Russian Republic of Tatarstan. He has an extensive experience in the area, working with Aerospace companies such as Russian Aerospace Agency - ROSAVIAKOSMOS, and French Space Agency - ONERA. In 2001-2007 Dr. Naoumov worked with Mechanical, Aerospace and Biomedical Engineering Department at University of Tennessee (UTK) and supervised the UTK engineering students in the design and construction of Lunar Rovers in the framework of NASA Great Moon Buggy Race Project with the competition at the Marshall Space Flight Center in Alabama. His teams were among top three twice (Silver Medal in 2003 and Bronze Medal in 2006) of all university teams from across the U.S. Starting 2007 he is affiliated with Central Connecticut State University (CCSU) Department of Engineering. His research areas are: Rocket and Aircraft Propulsion; Aerothermodynamics; Chemical Kinetics; Combustion Analyses; Thermo-chemical Non-equilibrium Flows; Internal Combustion Engines; Thermal/Fluid Systems; Numerical Simulation of Combustion and Flow; Microgravity Fluid Flow and Phase Change Heat Transfer. He is teaching the following disciplines: Propulsion; Advanced Propulsion; Combustion; Aeronautics; Heat Transfer; Applied Fluid Mechanics; Instrumentation; Thermodynamics; Senior Capstone Design Projects. Dr. Naoumov initiated a Moonbuggy project at the CCSU and supervised its team that took part in the 16th Annual NASA Great Moonbuggy Races in April 2009.

\section{Zbigniew Prusak, Central Connecticut State University}

Dr. Prusak is a Professor in the Department of Engineering at Central Connecticut State University in New Britain, CT. He teaches courses in Mechanical Engineering, Manufacturing Engineering Technology and Mechanical Engineering Technology programs. He has over 10 years of international industrial and research experience in the fields of precision manufacturing, design of mechanical and manufacturing systems and metrology. Dr. Prusak received M.S. Mechanical Engineering from Technical University of Krakow and his Ph.D. in Mechanical Engineering from University of Connecticut. E-mail: PrusakZ@ccsu.edu 


\title{
NASA Moonbuggy Senior Design Project as an Assessment Tool and Potential Career Path in Aerospace
}

\begin{abstract}
At Central Connecticut State University (CCSU), mechanical engineering senior design course sequence requires completion of two-semester capstone design project. Senior Project I a research class prefaces and is intended to prepare students for Senior Project II the final design project. The focus of this paper is to share our experience in using the NASA sponsored Great Moonbuggy Race Program as a Capstone design project, and to show how to use such a comprehensive design experience as an assessment tool addressing most ABET Criterion 3 a-k program learning outcomes, and its impact on students long terms career objectives. The project is designed to imitate real-world workplace environment; students are divided into four different independent groups, namely, frame, transmission, steering, and suspension, all of which report to a project manager who oversees the execution plan and coordinates between the teams, and manages day-to-day operational aspects of the project and scope. The Moonbuggy vehicle must satisfy not only functionality and strength, but also a set of geometrical and physical constraints such as weight, size, number of passengers, and power source.
\end{abstract}

Students' reflections and feedback demonstrate that this project is very suitable in offering graduating seniors unique opportunities to improve their analytical abilities, develop design, organizational, and project management skills, gain experience in working in multi-disciplinary teams, solve cutting-edge engineering problems, and familiarize themselves with aerospace challenges. Numerous other skills acquired in this project, such as leadership, managerial and interpersonal skills, competition, mitigation of team conflicts and communication problems, are expected to have a positive impact and pave the way for a successful career as practicing engineers.

\section{Introduction}

Seniors enter their last year having learned an extensive amount of material covering a wide variety of subject areas and skills. The senior capstone design project is based the knowledge acquired in engineering, science, and other general education courses. It provides students with the platform to move from individual course work to areas of applications and practice.

The first part of the paper provides an overview of the project significance, its goals, and objectives; in the second part a brief discussion of the design process is presented. This section is followed by students' reflections and the impact of this experience on their career objectives. The fourth part of this manuscript demonstrates the use of the project as a successful assessment tool, followed by some concluding remarks.

\section{Project Background}

The Bachelor of Science in Mechanical Engineering (BSME) at CCSU is designed with two concentration areas contained within the general degree offering. Through deliberate choice of electives; students can opt for specializing in manufacturing or aerospace studies. A specialization allows students to tailor the program to meet individual goals or interests, as well as, to address the changing needs of the industrial employers. 
CCSU is in a very close proximity of Connecticut-based United Technologies Corp. (UTC), and its Hamilton Sundstrand, Pratt \& Whitney, and UTC Power divisions. Over the years, UTC has played a vital role in many aspects of the US's aerospace program. One of the main goals of CCSU initiatives is to cater to the potential employers of our graduates. The project emphasizes many attributes that employers look for in their new hires. It prepares students to address and tackle complex and interdisciplinary design problems, to work in diverse teams, to acquire project management skills, and to present their findings to peers, faculty, industrial partners, and sponsors. Therefore, the implementation of this exciting NASA education-based program into the senior capstone real-world design challenge helps in engaging students in solving aerospace related technical challenges, strengthening the future workforce of the local and nationwide aerospace industries.

The annual Great Moonbuggy Race is organized by NASA Marshall Flight Space Center in Huntsville, Alabama. It is sponsored by corporate leaders in aerospace industry such as Lockheed Martin, Northrop Grumman, and Boeing to mention a few. The list of competitors of this program which started 17 years ago includes students from high schools, and college level as well students from several foreign countries. The program addresses design, fabrication, assembly, and road tests of a Moonbuggy where students are required to design a vehicle that satisfies numerous size, weight, and power constraints.

\section{Problem Statement, Goals and Objectives}

The most significant part of the senior year is the capstone design project. In the capstone experience, engineering students have the opportunity to go out of the individual course work box to solve multidisciplinary open-ended problems that are not tied up to a certain area in particular. The main design objective of this project is finding alternative solutions to the problems faced by NASA's original Moonbuggy team. Each Moonbuggy is human-powered and must be capable of carrying two students, one female and one male, over a half-mile simulated lunar - terrain course, including “craters”, rocks, "lava” ridges, inclines, and "lunar" soil. There are several requirements and design constraints that are included in the Moonbuggy:

1- Vehicle should be human - powered, energy - storage devices are not allowed;

2- The un-assembled vehicle must be collapsible in a volume with maximum dimensions of 4’x 4' $x$ 4'.

3- The assembled vehicle must be able to be lifted and carried 20 feet by the two passengers without any aid;

4- The maximum width of the assembled vehicle should be not more than 4 feet, including wheels;

5- Vehicles, or parts of vehicles, not constructed by the entering team are not acceptable; and

6- Vehicles that have been previously entered into the competition should contain major design modification to improve performance.

As comprehensive design experience, the Moonbuggy project offers seniors with opportunity to use the knowledge acquired in science, mathematics, engineering subjects, and other general 
education courses in the curriculum. The use of numerous computational tools such as FEA, CAD, statistical software, project management in engineering practice is highly emphasized. Often times, students use software that they were never exposed to, subjects that were not covered, literature review, and similar activities which encourages the life-long learning skills. Additionally, skills like working in teams, effective communication in oral, written, visual, and graphic modes are thoroughly addressed. These competencies represent the core of the ABET's $a-k^{1}$ program learning outcomes, that provide students with a strong platform for launching a successful engineering career, thus helping in meeting the program educational objectives.

Project also covers all steps of design process (from idea generation to design, fabrication, and competition), and provides practical application of engineering principles to real-world design challenges, students gain a valuable experience in:

1. problem identification and solving,

2. conceptual and detailed design,

3. procurement and fabrication,

4. resource and project management,

5. product testing,

6. developing oral and writing skills: report writing; presenting findings and vehicle design to peers, professors, and judges

7. outreach activities

\section{Project Activities Description}

The fall 2009 Moonbuggy frame team examined the frame designed by the last year's team. Upon inspection of the original design ${ }^{2}$ shown in Figure 1 and using the feedback of 2008/2009 team members, it was determined that the basic frame should be modified to meet the vision of the new group.

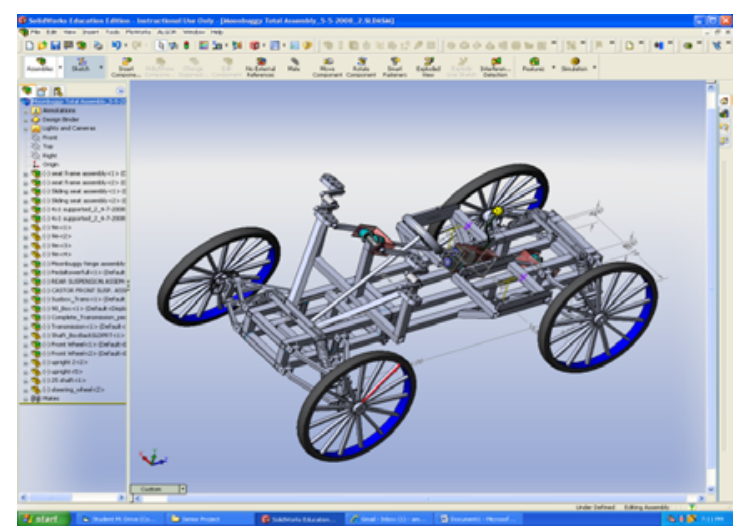

Figure 1: First version of Moonbuggy design

The new team reconsidered even conceptual schematics, proposed rear steering and front wheel drive to reduce mass of transmission, reduce the length of main transmission chain and simplify the Moonbuggy vehicle assembling in 4' $x 4^{\prime} \times 4^{\prime}$ cube (Figure 2 and Figure 3). 


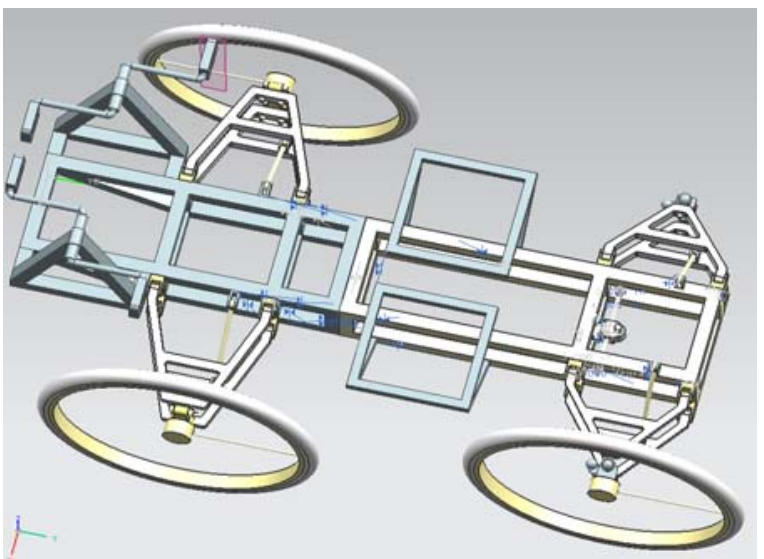

Figure 2: Revised Design of the Moonbuggy

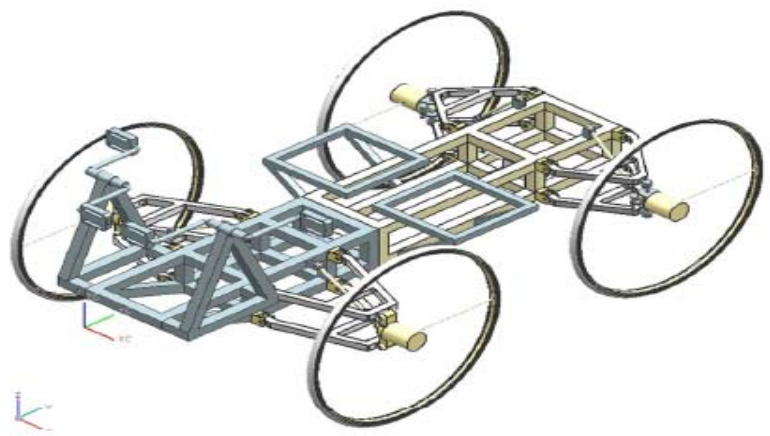

Figure 3: Revised Design of the Moonbuggy

The frame maintained its rectangular shape as per the original design. The A-arms attachments for the front suspension shown in Figure 4 were moved closer to the buggy's hinge point, which put more weight closer to the riders. In the final designing stages of the Moonbuggy frame, the team opted to slope the bottom upward allowing for more ground clearance, and fewer frame members to weld, resulting in a slight reduction in weight for the total system.

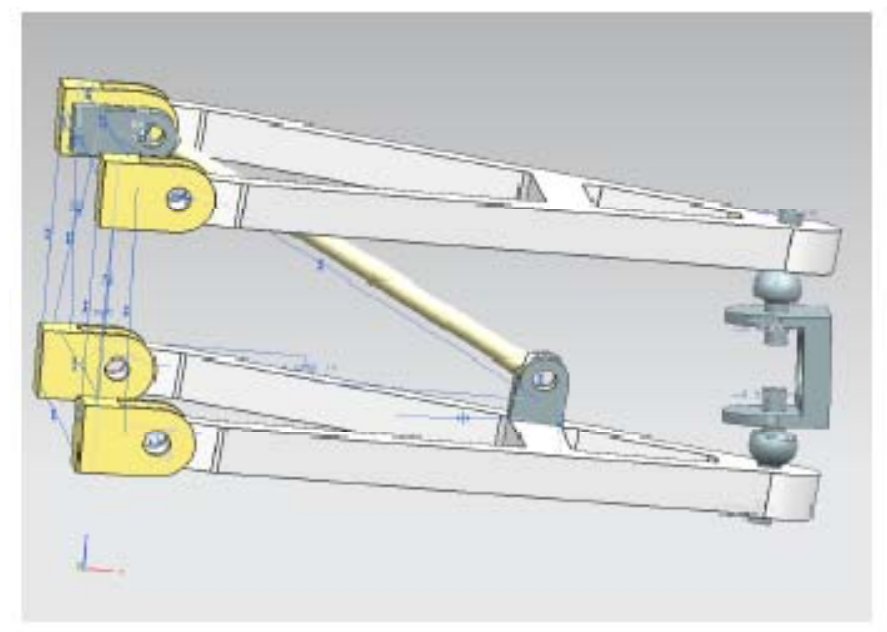

Figure 4: A-Arm design

Pedal towers were attached to the front part of the frame to allow the center of the pedal towers to align with the center of the seats. Attaching the pedal towers in this way allowed for the buggy to fold neatly in two, while still keeping within the maximum 4'x4'x4' space allotted under the rules of the competition. The vertical supports in both power, and steering frames allowed for strength where the A-arms are attached for the Moonbuggy's suspension. These supports also provided convenient locations for the attachment of the vehicle's payload, defined in the race's rules ${ }^{3}$.

Numerical analysis (Figure 5 and Figure 6) included application of 25-pound-force loads at each location of A-arm attachment, four points on each side of the buggy, perpendicular to the frame, along with a 75-pound-force load at each pedal tower, parallel to the ground. The 
displacement analysis demonstrated that the maximum deflection occurs at the top of the pedal towers, where the drivers apply substantial force. With a displacement of just under 0.030 ” at its worst, there is no major concern for the stability of the Moonbuggy vehicle under this loading in relation to displacement ${ }^{4,5}$.

Stress diagram shows that vehicle undergoes the maximum stress at the points where the rear of the pedal tower extenders meets the sides of the frame. At approximately $2260 \mathrm{lbf} / \mathrm{in}^{2}$ though, the team decided the potential stress resulting here was acceptable. All welding of the frame, Aarms and pedal towers was done by team members.

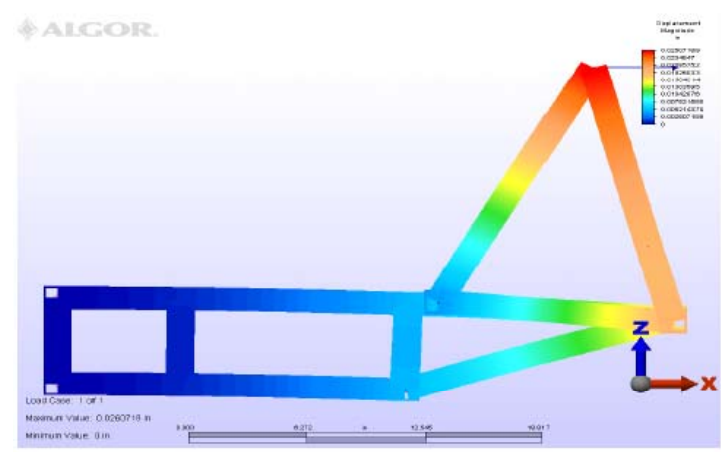

Figure 5: Stress analysis of the front part of the frame-Side view

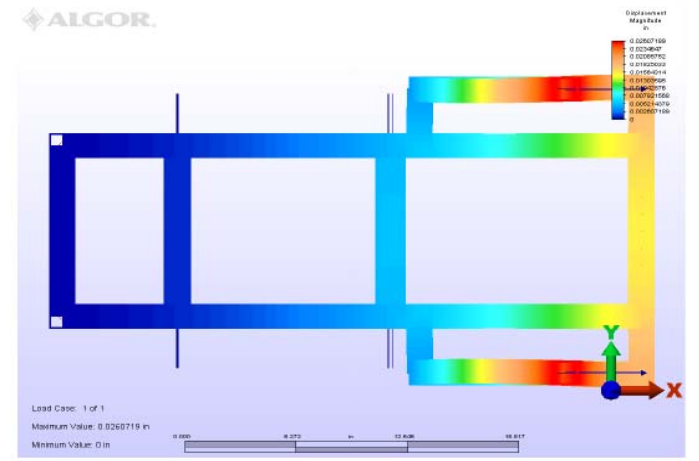

Figure 6: Stress analysis of the front part of the frame-Top view

The design of transmission system, proposed by transmission team consisted of two stages. The first involved transmitting the rotation from the pedal towers to a middle shaft, and the second was in transferring the rotation from that shaft to the differential gear and then to the wheels. During the research, the transmission team encountered problems with the simple design of the drive system. Most buggies have rear wheel drive. The buggy was long and the pedal towers were mounted in the front. That requires long chains and multiple shafts to transfer the rotation to the rear wheels that could cause the chain "fall down" from the sprockets during the races and Moonbuggy assembling in 4'x 4' $\mathrm{x} 4^{\prime}$ cube. The team decided to eliminate this problem by having front wheel drive.

Pedal towers were designed and made from 1.5”x1.5” square aluminum tubing as shown in Figure 7. Bearing housing was welded to the top of the towers with a bearing inside connecting the cranks. A keyed steel shaft was mounted using bearings on the frame below the pedal towers. Three sprockets were installed: two freewheels connected to the pedal tower, and one connected to the differential gear borrowed from Go-Cart as depicted in Figure 8. Universal joints and steel shafts were used to connect the differential to the wheels and provide the flexible angle between main shaft and half-shafts (Figure 7 and Figure 8). 


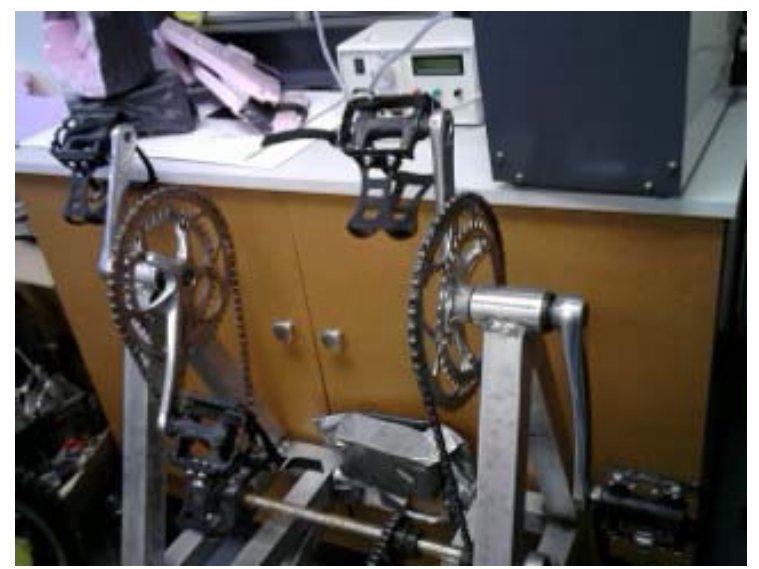

Figure 7: Pedal towers and transmission

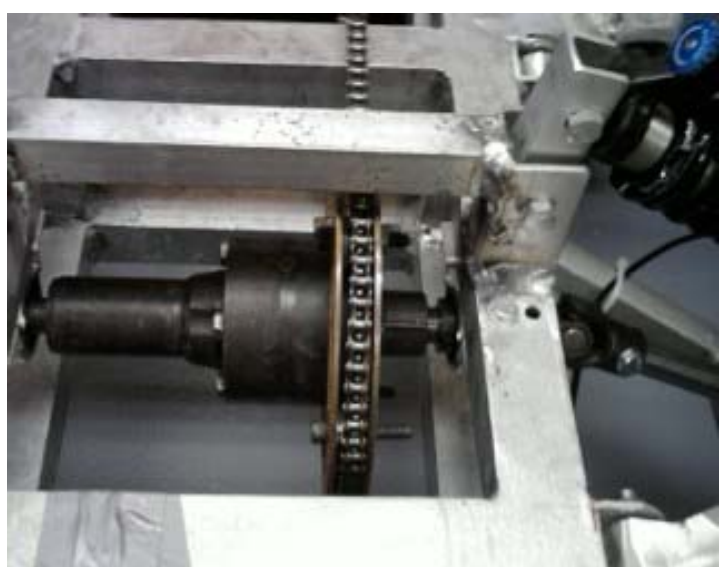

Figure 8: Transmission and differential

The suspension system design was settled upon use a Short Long Arm (SLA) conception (Figure 9). The advantage of the SLA or "double wishbone" A-arm system is that it has greater stability while cornering and it is fairly easy to work out the effect of moving each joint. The shock absorbers - FOX DHX Air SHOX 5.0 were attached via bolts through shock mounts on the frame and on the aluminum plates on the lower A-arm stress as the steel. The wheels were attached to the entire assembly through the axle and brackets on each side machined from solid aluminum and attached to the A-arms via universal joints (Figure 10). Regular bicycle brakes were used on the front wheels

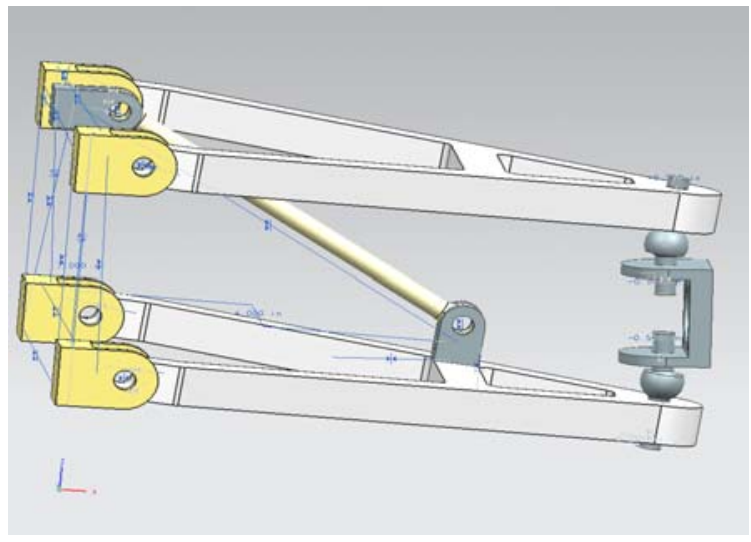

Figure 9: A-Arm design (repeated)

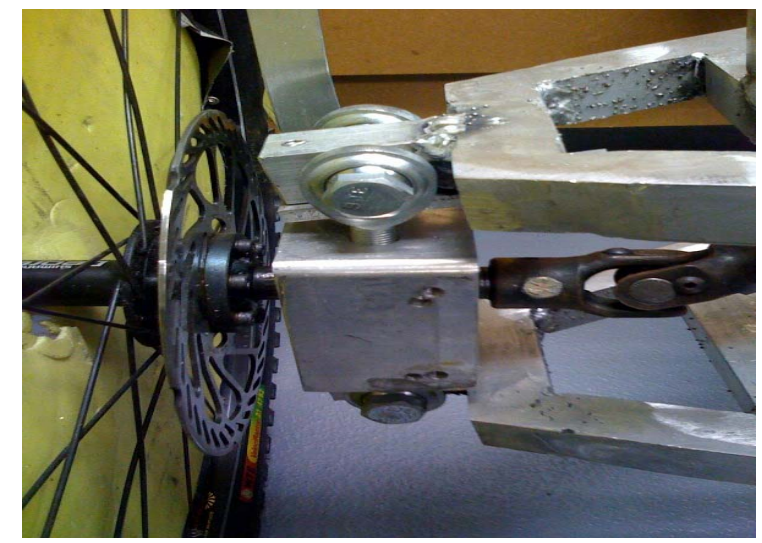

Figure 10: Wheels and brakes

The orientation of the steering system with respect to the drive system was the first decision that the steering team needed to make. Based on the front drive wheels design, there were two approaches to combine steering and drive systems: front wheel steering and/front wheel drive, rear wheel steering/front wheel drive. Front wheel steering system provides the driver with a more intuitive driving experience similar to operating a standard automobile. Designing a front wheel steering system would require fewer parts in the system and less design complications. However in considering the Moonbuggy system as a whole, the steering team has designed a rear wheel steering configuration for the following reasons: rear steering requires just a few extra 
parts compared to front one; combining of drive and steering system in the front of the vehicle adds additional risk of breakdown caused by the chains getting stuck while driving over an obstacle, inadvertently steer the vehicle in an undesired direction ${ }^{4}$

The steering gearbox as depicted in Figure 11 can move 2" in each direction from the centerline position. Three quarters of a revolution is required to move the shaft from the steering gear box from the centerline position to one end, and consequently $1 \frac{1 / 2}{2}$ revolutions is required to move the shaft from the maximum far end of one side to another. To increase the performance of the Moonbuggy steering system an additional gearing system as depicted in Figure 12 was added to the steering gear box. The purpose of this additional gear system was to reduce the number of revolutions required for the wheel to reach its maximum angle normal to the vehicle. This will allow the operator to make turns quicker and react faster to environmental hazards presented on the course. The steering was fabricated using two $1 / 4$ inch thick aluminum plates that supported the steering gearbox and the mechanical steering components. The 18 tooth sprocket was attached to the Steering Gearbox shaft and was link by the chain to the 28 tooth sprocket. The 60 tooth sprocket was attached to its own shaft and linked to the 14 tooth sprocket. This combination of chains and sprockets allows the gearbox shaft to turn 540 degrees when the 60 tooth sprocket rotates about 90 degrees. The 60 tooth sprocket was connected to a steering lever by a two tie rods. The gearbox was connected to the wheels through aluminum tie rods and steel L-brackets as shown in Figure 11.
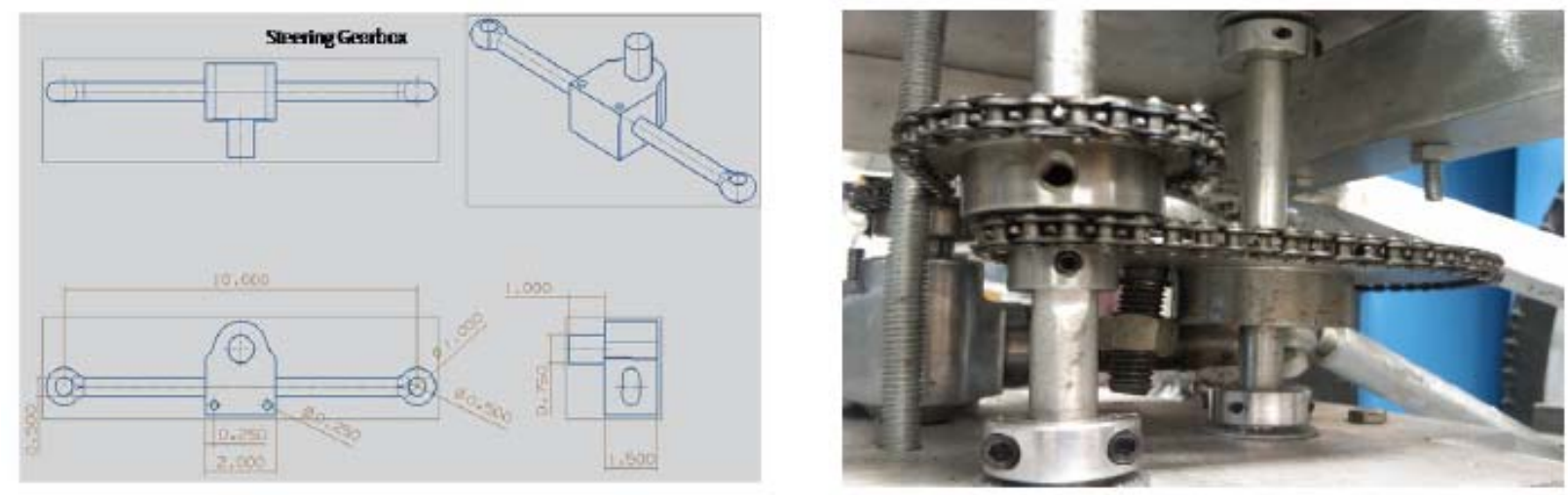

Figure 11: Steering Gearbox

\section{Students Feedback and Reflections}

The following paragraphs include a verbatim feedback of the fall 2009 team leader:

"The purpose of this letter is to provide feedback about my experience with the Moonbuggy Project at the project midpoint. My point-of-view is from my role as project manager, where I managed Moonbuggy vehicle design, material, tools, and parts ordering, parts fabrication, and Moonbuggy systems assembling, and generally assisted Dr. Naoumov with coordination and execution of the design/build program. My intent is to clearly identify the suitability of the project to the senior capstone course requirements and make suggestions that may improve the program. 
Overall the Moonbuggy Project is solid capstone program that contains most of the basic elements of a real-world engineering project. To support my opinions I will list the positive attributes of the program followed by the pitfalls I have encountered.

1. Opportunity to apply most aspects engineering and engineering technology (design, solid modeling, engineering, manufacturing, testing and analysis)

2. Opportunity to apply basic and sophisticated calculations (geometry, physics, structural analysis, mechanics, statics, dynamics, and statistics)

3. Exposure to real-world engineering team dynamics (deliverable work assignments, work cell coordination, leadership responsibilities, and decision making)

4. Alternative designs can be considered and compared, which can tailor course content for individuals or sections, i.e., electric or fluid propulsion

5. Can be applied to aerospace careers when considering: use of structural aluminum, common composites, low factor of safety design, compact design, strength to weight ratio, symmetry in design, center of gravity payload, design for maintenance, fastening systems, performance for power available, and performance testing and evaluation

In short, the Moonbuggy Project has been a fully engaging engineering program. The nature of program provided opportunities for application of engineering concepts and technologies which were only limited by students' time and motivation.

The pitfalls and hindrances encountered mostly resulted from the transitional effects of curriculum and department policy, but not all.

1. There was no predominate solid modeling choice among the students. Unigraphics was agreed upon but it became clear that there was a relatively low proficiency across the board. Fortunately one student who uses ProE routinely at work was able to create the solid model. My ProE proficiency was not adequate until the latter part of the semester as I completed the ProE course. This general lack of skills was an early hindrance.

2. The recent FEA transition to ANSYS created a learning curve for the students attempting to conduct structural analyses since their training was with ALGOR. This created a hindrance for FEA support during the design phase. As with ProE my ANSYS skills improved as I progressed through the FEA course.

3. The need to re-familiarize students with the machinery operation was a hindrance. (A short refresher conducted by the technical staff would be helpful).

4. The need to procure all tooling did create some work stoppages. (It may be helpful to establish a preferred method of tooling, i.e., bits, inserts, or disposable tools). 
As stated above, the Moonbuggy Project is a solid program, but the structure of the program should evolve to fit the typical non-resident engineering student. I have two major suggestions; the program should be highly structured to enable students to stay on schedule. And, the use of a graduate assistant would streamline progress as well as the evolutionary process, and would allow the professor to attend to the higher order concepts. Lastly, there are a full range of engineering concepts and applications embedded within the program, but to realize the potential of the program there must be at least four highly motivated students in each cycle.

My personal reflection about the project has been very positive, as a student and as an individual. It has been enriching to complement my mechanical know-how with engineering concepts, and great fun to actually build a working prototype. The atmosphere of the project has been very good mostly because the camaraderie and team spirit among the students has been exceptional. It has been truly enjoyable and interesting to work with this group of diverse young people.”

\section{Assessment and Evaluation of Student Learning}

For capstone design experiences, the program learning outcomes assessment strategies are significantly different than those that are typically be used in other lower level coursework. Based on previous work by Prusak ${ }^{6}$ Accreditation ABET 2000 guidelines and input from Industrial Advisory Board (IAB), the Department of department of Engineering has developed a rubric for systematic, quantitative evaluation of the Program Learning Outcomes ${ }^{1}$ (PLO's) appropriate for capstone design experiences.

The plan ${ }^{7}$ focuses on several evaluation metrics of the competencies expected from a graduating senior ${ }^{6,8}$.These competencies include ability of the students to identify technical challenges, and information relevant to projects posed by potential employers, apply the knowledge gained through the course of study to address the technical challenges, and communicate their findings to peers, faculty, and Industrial Advisory Board (IAB).

In the research part of Senior Project course, students are asked to submit a proposal that clearly defines and articulates an implementation plan of the Moonbuggy project defining all major technical and logistic impediments associated with carrying the project through to completion. To support the possibility of experimental research, as well as to assist in the project phase, both Design of Experiments (DOE) and Project Management (PM) methodologies are reviewed invoking the in-house software packages Minitab ${ }^{\circledR}$ and MS Project ${ }^{\circledR}{ }^{9}$. The objective is to help students develop good time management skills, work consistently and are able to stay on schedule.

According to Robert C. Moore ${ }^{10}$, "the capstone course is an opportunity for students to demonstrate that they have achieved the goals for learning established by their educational institution and major department. The course should be designed to assess cognitive, affective, and psychomotor learning and to do so in a student-centered and student-directed manner which requires the command, analysis, and synthesis of knowledge and skills.”

In the light of the above, the Moonbuggy used as capstone project is an effective instrument to measure the attainment of Program Learning Outcomes. The project is very comprehensive and 
open-ended; which enables students to demonstrate the attainment of a wide variety of technical and non-technical competencies.

The senior project evaluation rubric has been in use for a number of years within engineering technology programs. The rubric is used during students' presentation of their final findings. The course instructor and presentation evaluators (other faculty or Industrial Advisory Board members) fill out the rubric during the final presentations. The goal is to keep the evaluation process as objective and consistent as possible which is difficult in practice. The competencies are evaluated on a scale of 1 to 4 , where 1 is poor, and 4 is exemplary. Figure 12 and Figure 13 illustrate the evaluations of the spring 2009 Moonbuggy project by two faculty members. Both evaluations are essentially consistent, with the exception of science/math and part of the communication skills.

The first column from the left in Figure 12 and Figure 13 illustrates the attainment level of the program learning outcomes listed below:

1. Ability to design the Moonbuggy and its various components to meet the design constraints set by the organizing agency;

2. Ability to use numerous computational and engineering analysis methods;

3. Ability to apply advanced mathematics, probability theory, design of experiments, and project management skills.

The design of the Moonbuggy involves a considerable set of relationships among four subsystems (frame, transmission, suspension and steering), each of which has many components. In this project the four main subsystems are interrelated and dependent on each other. Students were able to explore and analyze various configurations, and then decide on the best course of action. For example, students considered two alternative steering systems: front-wheel and rearwheel mechanism. This approach applies to many other components, subsystems, and mechanisms. Although on a limited scale, the Moonbuggy provided students with the ability to exercise and implement the iterative nature of engineering design. The assessment process was also comprehensive; students were judged on their ability of proposal writing, literature review, design alternatives, and decision making as shown in Figure 12 and Figure 13. 


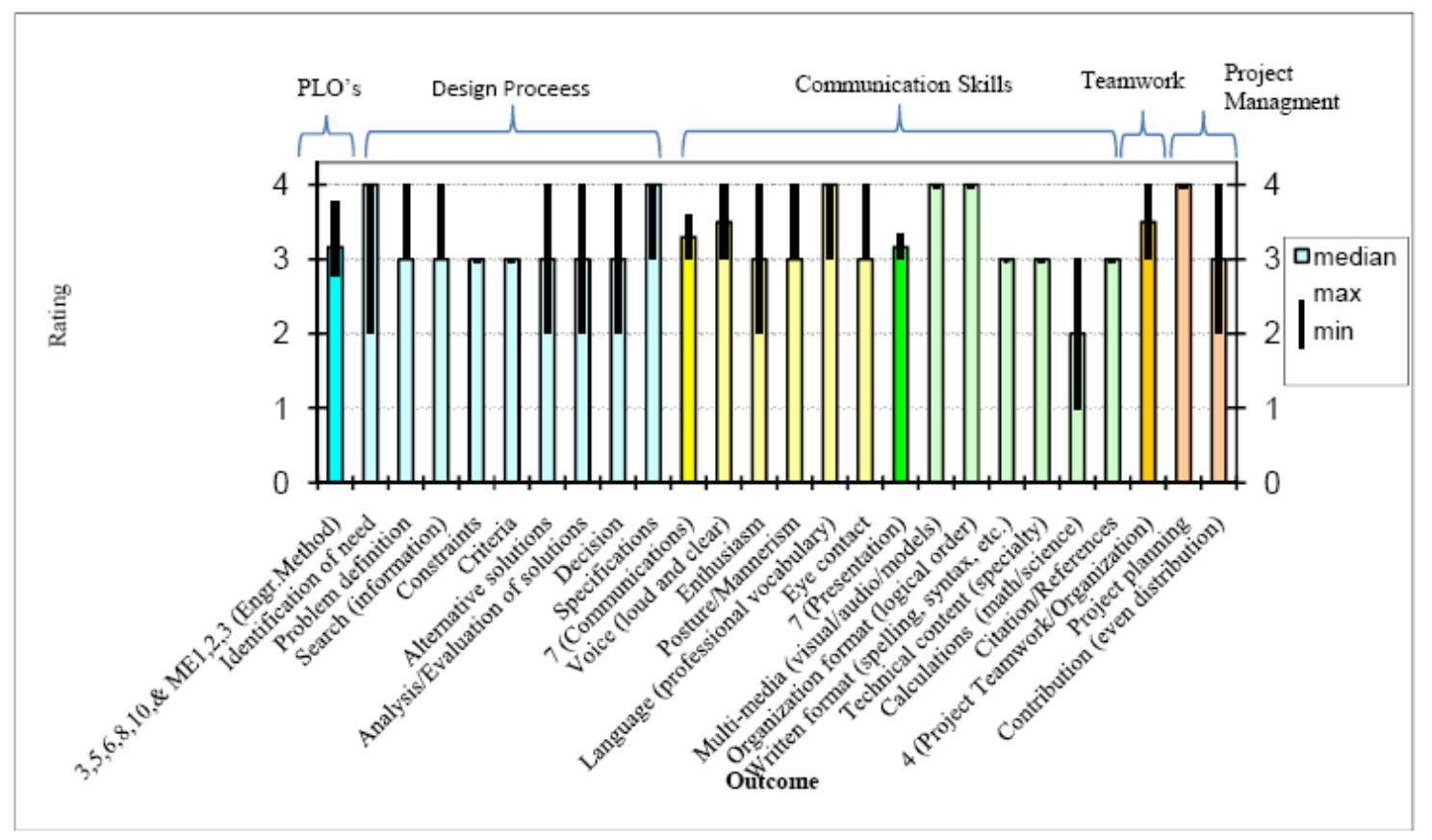

Figure 12: Senior project evaluation-Evaluator I

Rating of outcomes achievement ME 498Senior Project II

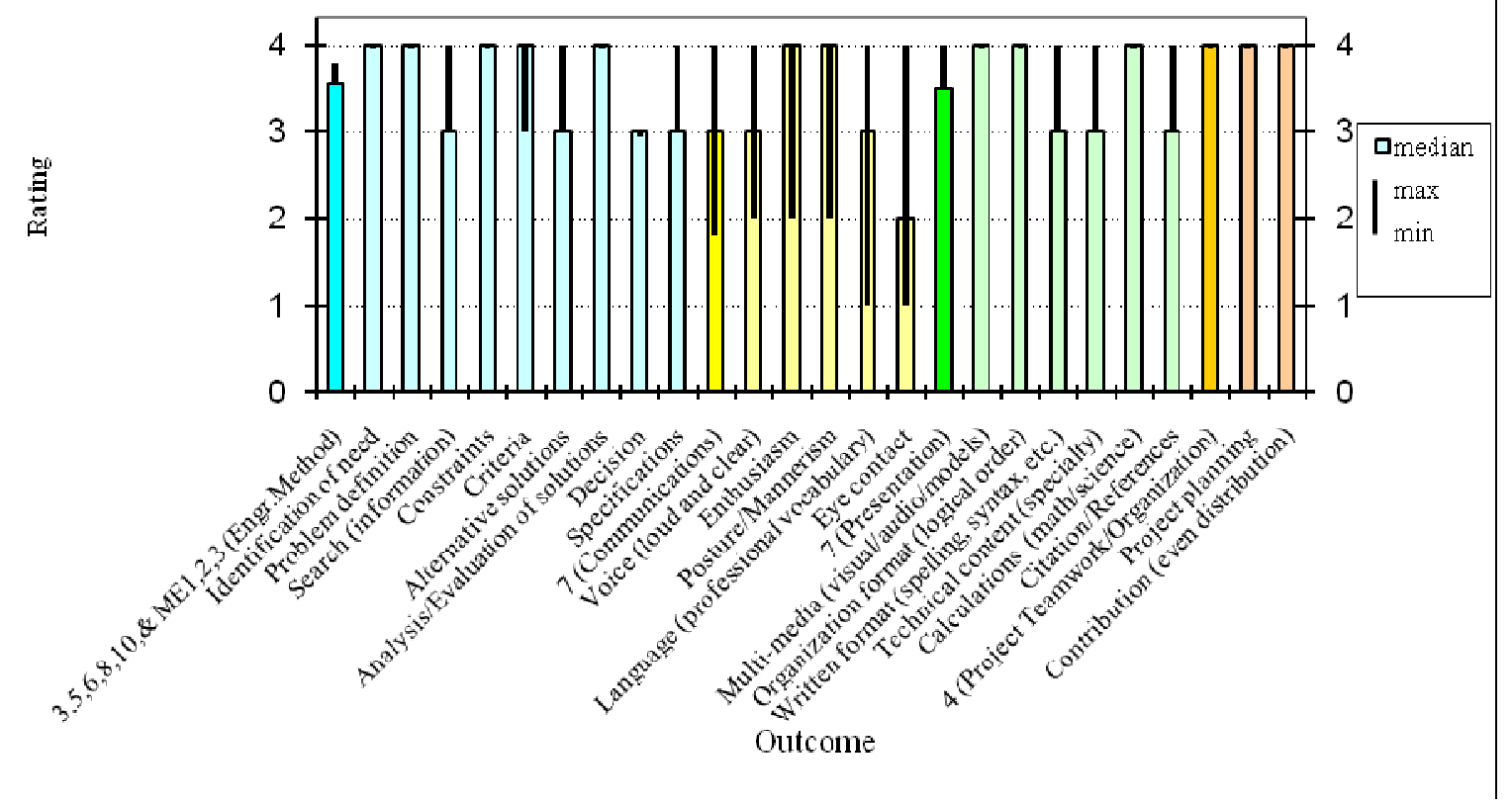

Figure 13: Senior project evaluation-Evaluator II

Designing complex systems, such as Moonbuggy rover, necessitates coordination of activities of all teams during design process. Additionally, once the design is completed, it is essential to present the findings to peers and an instructor. Effective communication skills are the vehicle by which such coordination could be achieved. Ability to communicate the findings, working in 
teams, organization, and time management are highly emphasized in this project. The rubric is a tool used for overall assessment of the written, oral, and visual presentation skills, including body language, voice, and manners. The assessment results of these competencies are presented in Figure 12 and Figure 13.

\section{Conclusions}

Incorporating of NASA Moonbuggy Program in the departmental senior capstone design demonstrated that the program is suitable to cover all aspects of a comprehensive capstone design activity, from brainstorming phase and conceptual design to product manufacturing, assembling, and participation in the competition. The project activities are organized to simulate the real-world design environment, where the design is carried out by a several departments within an organization. Successful completion of such complex task requires strong leadership represented by the project manager, and continuous coordination, full collaboration, effective communication between different design teams and team members.

Presentation of the project to the industrial advisory board, faculty, and the Connecticut State Space Consortium, provided students not only with networking opportunities to leading aerospace industries, but also with possibility to answer questions posed by practicing engineers, and managers. In addition, the project provided students with the opportunity to carry out several hands-on activities such as welding, assembly, testing. Such an experience provides a smooth transition from academic environment to engineering practice.

\section{Bibliography}

1. ABET. Criterion for Accreditation of Engineering Programs, 111 Market Place, Suite 1050, Baltimore, MD: Accreditaion Board of Engineering and Technology; 2009.

2. Krystofolski A, Batterson B, Budarz S, Clark R, McNamara K, Miller M, Fagan J, Thomas Bianchi, Peters C, Brusseau K and others. NASA Moonbuggy Lunar Vehicle Design - 2008. Project report. New Britain: Central Connecticut State University; 2008.

3. Six F. Moonbuggy Rules and Penalties. NASA; 2008.

4. Hrenko J, Danenberg A, Summers K, Shaw H, Varghese P, Geagea E, Cook C, Elhwali A, Cegelka N. 2009 Great Moonbugg Race. Project report. New Britain: Central Connecticut State University; 09.

5. Naoumov V, Al-Masoud N. NASA Project in ME Senior Capstone Design Class: Experience and Pedagogical Issues. In: AIAA, editor. Aerospace Science Meeting and Exhibit. Volume 47. Orlando: AIAA; 2009. p 1-8.

6. $\quad$ Prusak Z. Challenges to Future Engineering Professionals - How to Prepare Students to Face Them. 1998; Seattle, WA. American Society for Engineering Eduation.

7. Lema L, Baumann P, Prusak Z. In-common Methodology for Objective- and Outcome-based Programs Assessment. 2005; Portland, OR. American Society for Engineering Education.

8. Prusak Z. Application of QFD in Engineering Education: Assurance of Learning Outcomes Fulfillment. 2007; Williamsburg, VA. QFD Institute.

9. Al-Masoud N, Baumann P. Development and Implementation of an Integrated Outcom-based Assessment Plan for a New Engineering Program. 2009; Austin, TX. American Society of Engineering Education.

10. Moore RC. "The Capstone Course," In Assessing Media Education: A Resource for Educators and Administrators, ed. Christ WG, editor. Erlbaum: Elizabethtown College; 2005. 